\title{
Role of fetal craniotomy in modern day obstetrics: case series
}

\author{
Somila Xess*, Shipra Shrivastava
}

Department of Obstetrics and Gynecology, GMC Ambikapur, Chhattisgarh, India

Received: 09 February 2019

Accepted: 06 March 2019

\section{*Correspondence:}

Dr. Somila Xess,

E-mail: somilaxess05@gmail.com

Copyright: (c) the author(s), publisher and licensee Medip Academy. This is an open-access article distributed under the terms of the Creative Commons Attribution Non-Commercial License, which permits unrestricted non-commercial use, distribution, and reproduction in any medium, provided the original work is properly cited.

\begin{abstract}
Although obstructed labor in vanished from the western world where the destructive operations are obsolete and not needed, in developing countries like India obstructed labor with dead fetus and severe infection is a sad reality, and destructive operations are an essential part of obstetric practice and cannot be wished away. In many situations they should be a preferred option to cesarean delivery which needs much better facilities and greater morbidity. Here authors present a case series of three patients who reported with obstructed labour and IUFD. Fetal craniotomy was done and thus maternal morbidity reduced. Craniotomy offers less postpartum morbidity, lesser expertise and resources and therefore better in cases presenting with obstructed labour and dead baby in developing countries.
\end{abstract}

Keywords: Craniotomy, Destructive procedures, Obstructed labour

\section{INTRODUCTION}

Unduly prolonged obstructed labor with the fetus jammed in the pelvic cavity beyond any hope of spontaneous delivery is not seen in the developed countries today. But such a situation is prevalent in the developing countries across the continents. It plagues thousands of women every year and accounts for $8 \%$ of maternal deaths in developing countries but in developing countries, it ranges $4-70 \%$ of all maternal deaths and it is also associated to high perinatal mortality rate. ${ }^{1,2}$ In India $70 \%$ of our population lives in rural areas with barely any modern obstetric facilities. Antenatal care is mostly not available or not availed of for various reasons. The arriving parturient often merits the description of a woman in neglected obstructed labor with a dead fetus and distressed mother with dehydration, advanced infection and a uterus desperately trying to surmount the obstruction. Although obstructed labor in vanished from the western world where the destructive operations are obsolete and not needed, in developing countries like India obstructed labor with dead fetus and severe infection is a sad reality, and destructive operations are an essential part of obstetric practice and cannot be wished away. In many situations they should be a preferred option to cesarean delivery which needs much better facilities and greater morbidity. Government Medical college Ambikapur is a tertiary care hospital in Chhattisgarh where most of the cases are unbooked, tribal, belonging to rural areas and nearly $80 \%$ are referred from nearby $\mathrm{PHC}, \mathrm{CHC}$, or delivery being conducted by unskilled persons. Due to poor transport facilities and long distance most of them are brought late in labour with ruptured membranes, infected, and in state of exhaustion. Therefore, the present study was done to highlight the importance of fetal craniotomy in minimal resource setting. The prime objective of the present study was to establish the role of fetal craniotomy in modern day obstetrics.

\section{CASE REPORT}

\section{Case 1}

32-year-old G2P1 with 38 weeks period of gestation, previous LSCS 3 years back presented with entrapment 
of after coming head of breech. On examination her vital parameters were stable with pulse of $120 / \mathrm{min}$, regular, febrile, BP of $120 / 90 \mathrm{~mm} \mathrm{Hg}$, RR of $24 / \mathrm{min}$. There was no scar tenderness. Female baby was delivered up to the trunk and her lower limbs and abdomen was bluish black. Heart sounds were not audible. Immediately, the woman was taken to the labour room and iv antibiotics and fluid given, delivery of after-coming head was tried with Mauriceau-Smellie-Veit manoeuvre (MSV). As the after-coming head could not be delivered with MSV technique, craniotomy was done from the left aspect of the nuchal prominence at the occipital bone behind the mastoid with the help of Simpson's perforator. After suctioning of $200 \mathrm{ml}$ of cerebrospinal fluid along with pieces of brain matters, the head was delivered spontaneously. Placenta was delivered by controlled cord traction. Vaginal wall and cervix were checked for signs of trauma. Bleeding from the uterus was controlled with uterine massage, Inj. Oxytocin 10 units IM. Foleys catheterization was done. Placenta was checked for its completeness. Baby was examined which revealed female baby with no obvious congenital anomalies .Patient was given iv antibiotics and discharged after 48 hours with catheter in situ and was advised follow up after 1 week during which the catheter was removed.

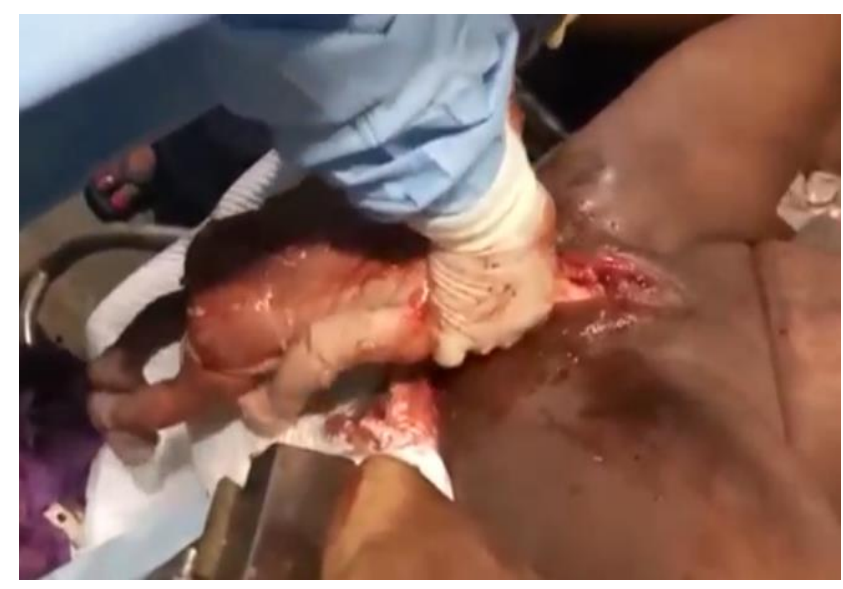

Figure 1: Baby delivered up to trunk.

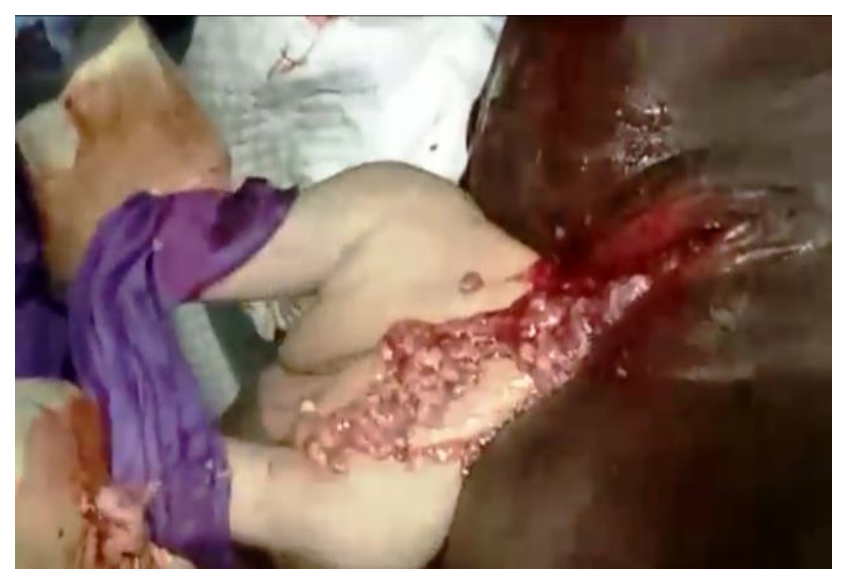

Figure 2: Craniotomy done with brain matter seen.

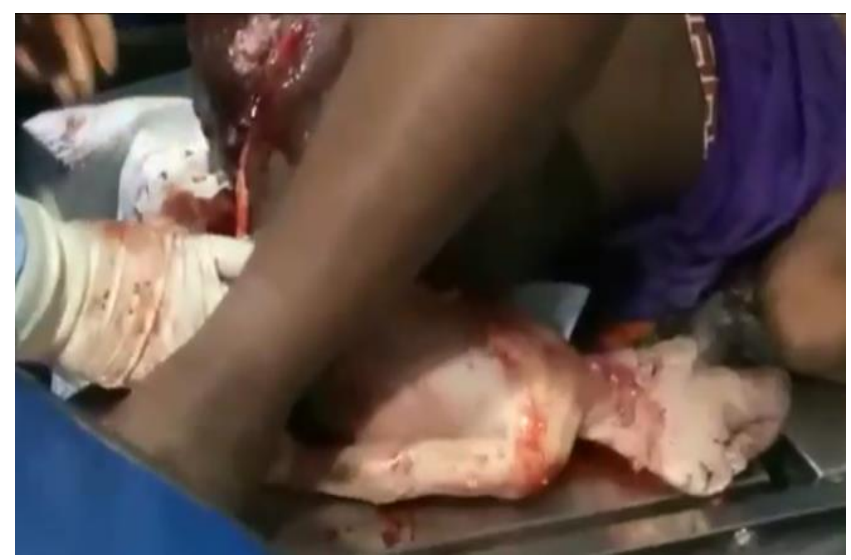

Figure 3: Delivery of dead fetus.

\section{Case 2}

25-year-old G1 with 40 weeks of gestation was admitted with full dilatation of cervix and non-descent of head for 6 hours. On examination vitals were stable with signs of dehydration.

Auscultation revealed no heart sounds. P/V examination cervix was dilated $10 \mathrm{~cm}$, fully effaced vertex at +2 station and big caput with narrow sub pubic arch, vagina was warm, oedematous and foul-smelling liquor. Decision of craniotomy was done, iv line secured, and fluid started, and antibiotics given. With the help of sharp pointed mayo's scissors, most dependent part was perforated as suture line could not be defined due to big caput, CSF drained out and contents evacuated, spontaneous delivery occurred.

\section{Case 3}

25-year-old G2P1 with $37+5$ weeks period of gestation, presented with obstructed labour and diagnosed case of hydrocephalus. She was vitally stable and FHS absent. So, craniotomy was done under all asepsis. CSF was drained and brain matter suctioned followed by delivery of fetus.

\section{DISCUSSION}

Destructive procedures are the operations that are designed to diminish the bulk of the fetus so as to facilitate easy delivery through the birth canal.

\section{Modern obstetrics}

- It is evidence-based practice of obstetrics.

- Accountable and unbiased.

- Offers best possible outcome to mother and baby.

- It has least morbidity to mother and new born.

- Nearly litigation free.

- Modern obstetrician must be expert in destructive operations and second stage L.S.C.S. 


\section{Destructive operations}

- Needs few instruments and simple anaesthesia.

- Uterus remains intact, ( no L.S.C.S. scar ). Subsequent pregnancy will be safer. Operative morbidity is lesser.

- Hospital stay is shorter.

- They need to be taught to young doctors

Destructive procedures are unpleasant and unacceptable level of maternal traumatic and psychological morbidity but with lesser complications than advanced second stage caesarean section. The main indications for fetal craniotomy are: cephalic presentation with obstructed labour, hydrocephalus in a living fetus, interlocking head of twins and aftercoming head of breech. Cephalopelvic disproportion is the most common indication for craniotomy. ${ }^{3,4}$ Most of the victims of obstructed labour are teenage pregnant women, unbooked primigravida with poor socioeconomic background and lack education. ${ }^{5,6}$ Entrapment of after coming head during the vaginal delivery of breech is one of the most serious complication. Unlike in the delivery of baby with vertex presentation where molding occurs, the head of fetus in breech presentation must come through the birth canal without having any molding. So, in this emergency situation choices among optimal options available need to be made very quickly. To release the entrapment, one of the following measures may be tried:

- Attempt the Dührssen incisions by cutting the cervix at 2, 6, and10 o'clock to increase the size of the cervical aperture,

- Use of agents like betamimetics, nitroglycerine or inhalational anaesthesia for uterine relaxation, or

- Perform an emergency Cesarean section (abdominal rescue). ${ }^{7}$

If the fetus is already dead or unsalvageable as in our case, decision and attention can be given ensuring a safety of mother and for good maternal outcome. At this moment destructive procedure like fetal craniotomy can be carried out to deliver the after coming head.

\section{Prerequisites}

- $\quad$ Fetus is dead (hydrocephalus excluded)

- Two fifth or less head Palpable above the brim

- Head is impacted

- Cervix is at least $7 \mathrm{~cm}$ dilated

- Uterus unruptured/no Imminent rupture 6.True conjugate not $<7.5 \mathrm{~cm}$.

Complications that can arise from craniotomy include atonic postpartum haemorrhage, vaginal and perineal tears, ruptured uterus, wound dehiscence or sepsis and maternal death. ${ }^{8,9}$ Arora et al from a medical college hospital Pondicherry reported in 1999, 33 destructive operations performed between 1981 and 1991-27 craniotomies, two decapitations, three eviscerations and one cleidotomy. ${ }^{10}$ Biswas et al from Kolkata reported a $1.17 \%$ (141 in 12,034 deliveries over a year) incidence of obstructed labor- $0.29 \%$ or 36 with dead fetus. $44.4 \%$ underwent craniotomy and $55 \%$ evisceration. Cephalopelvic disproportion was the commonest cause of obstruction. There was one traumatic rupture of the uterus but no maternal death. ${ }^{11}$ Singhal et al, from a medical college hospital in Haryana, reported 51 destructive operations done for obstructed labor with dead fetus over a 7-year period. Of these $68.62 \%$ women had craniotomies, $19.60 \%$ had decapitation, $7.84 \%$ had evisceration and $3.92 \%$ had cleidotomy. Two fetuses were groosly malformed, $49.05 \%$ weighed between 3 and $4 \mathrm{~kg}$, and $9.43 \%$ were macrosomic. $49.09 \%$ women developed complications like atonic postpartum hemorrhage, vaginal and perineal tears, puerperal sepsis, and urinary infection. There was no maternal death. ${ }^{12}$ Adhikari et al from a Medical College hospital in Kolkata report in 2005 a $0.56 \%$ incidence of obstructed labor (245/43906 deliveries) from January 1993 to December 1998. $63.27 \%$ or 155 were delivered by cesarean section and $36.73 \%$ or 90 had destructive operations. ${ }^{13}$ Gupta and Chitra from a Medical College hospital in Delhi compared 56 destructive operations for women arriving late in obstructed labor with a dead fetus done between 1985 and 1991 with 27 cesarean sections done in 1989 and 1990 for similar indications. They found that destructive operations had no maternal death, few complications, and short hospital stay while cesarean section had one maternal death, long hospital stay, need for blood transfusion, and more complications. ${ }^{14}$

\section{CONCLUSION}

It will not be wrong to say that, craniotomy is of value in places which deal with a large number of cases of obstructed labour and intrauterine deaths due to lack of adequate antenatal care and should not be abandoned totally. With fewer complications it does has a role in modern day obstetrics.

\section{Funding: No funding sources Conflict of interest: None declared Ethical approval: Not required}

\section{REFERENCES}

1. Chaudhuri A, Kamilya G, Santra D. Fetomaternal outcome in obstructed labor in a peripheral tertiary care hospital.Med J DY Patil Univ 2013;6(2):146-50

2. Cron J.Lessons from the developing world:obstructed labour and vesico vaginal fistula. Medscape Gen Med. 2016;5(3):14.

3. Udoma EJ, Ekanem AD, John ME, Ekanem AI .The role of institutional factors in maternal mortality from obstructed labour. Global J Med Sci 2003;2(1):13-7.

4. Osagie O, Azzan B. Destruction Operations. Progress in Obstetrics and Gynaecology. 1987;6: 211-21. 
5. Biswas A, Chakraborty PS, Das HS, Bose A, Kalasar PK. Role of destructive operations in modern day obstetrics. J Indian Med Assoc 2001;99(5):250-1

6. Adeoye IS, Dimejesi I, Onoh R, Bartholomew O, Ezeanochie M. Obstructed Labor in South East Nigeria Revisited: A Multi-Centre Study on Maternal Socio-Demographic and Clinical Correlates. J Women's Health Care. 2014;3(160):2167-70.

7. Wongwananuruk T, Rattanachaiyanont M. Entrapment of After-coming Head in Cesarean Breech Delivery of Term Pregnancy: A Case Report. Siriraj Med J. 2008;60(6):356-9.

8. Ekanem AD, John ME, Ekanem AI .The role of institutional factors in maternal mortality from obstructed labour.Global J Med Sci 2003;2(1):13-7.

9. IA, Gaya AS. Maternal and fetal outcomes in patients with eclampsia in Murtala Muhammed specialist Hospital Kano Nigeria. Annals Afri. Med 2011;10(4):305-9

10. Arora R, Rajaram P, Oumachigui A. Destructive operations in modern obstetrics in a developing country at tertiary level. Brit J Obstet Gynaecol. 1993;100(10):967-8.

11. Biswas A, Chakraborty PS, Das HS, Bose A, Kalsar PK. Role of destructive operations in modern day obstetrics. Journal of the Indian Medical Association. 2001;99(5):248-50.

12. Singhal SR, Chaudhry P, Sangwan K, Singhal SK. Destructive operations in modern obstetrics. Arch Gynecol Obstet 2005;273(2):107-9.

13. Adhikari S, Dasgupta M, Sanghmita M. Management of obstructed labor: a retrospective study. J Obstet Gynecol India 2005;55(1):48-51.

14. Gupta U, Chitra R. Destructive operations still have a place in developing countries. Int J Gynecol Obstet. 1994;44(1):15-9.

Cite this article as: Xess S, Shrivastava S. Role of fetal craniotomy in modern day obstetrics: case series. Int J Reprod Contracept Obstet Gynecol 2019;8:1679-82. 